www.jmscr.igmpublication.org

Impact Factor (SJIF): 6.379

Index Copernicus Value: 71.58

ISSN (e)-2347-176x ISSN (p) 2455-0450

crossref DOI: _https://dx.doi.org/10.18535/jmscr/v6i3.113

Journal Of Medical Science And Clinical Research

IGM Publication

An Official Publication of IGM Publication

\title{
Tension Pneumoperitoneum and Abdominal Compartment Syndrome Rare Complication of Percutaneous Radiological Gastrostomy, Case Report and Literature Review
}

\author{
Authors \\ Abbas AR Mohamed, MBBS, FRCSI, FICS, FACS ${ }^{1}$, Turki Atia Al Quarshi, MBBS, \\ Saudi Board ${ }^{2}$, Abdulsalam A Bin Hafiz, MBBS $^{3}$, MRCSI, Alharbi, Hatem Hussein $\mathbf{M}^{4}$ \\ ${ }^{1,2}$ Consultant General and Laparoscopic Surgeon, Department of Surgical Specialties, \\ $\mathrm{NGH}$-Madinah -KSA \\ ${ }^{3}$ Associate Consultant General and Laparoscopic Surgeon, Department of Surgical Specialties, \\ NGH -Madinah -KSA \\ ${ }^{4}$ Surgical Training Resident, Department of Surgical Specialties, NGH -Madinah -KSA \\ Corresponding Author
}

Abbas AR Mohamed, MBBS, FRCSI, FICS, FACS

Consultant General and Laparoscopic Surgeon, Department of Surgical Specialties, NGH -Madinah -KSA

\begin{abstract}
Tension pneumoperitoneum (TP) is defined as the massive accumulation of air in the peritoneal cavity, which results in a sudden increase in intraabdominal pressure. Various iatrogenic procedures are responsible for this complication (1). We report a case of tension pneumoperitoneum after percutaneous radiological gastrostomy (PRG).
\end{abstract}

Keywords: Percutaneous radiological gastrostomy, tension pneumoperitoneum, abdominal compartment syndrome.

\section{Introduction}

Tension pneumoperitoneum and abdominal compartment syndrome (ACS) are rare complications of percutaneous radiological gastrostomy. We report a case of tension pneumoperitoneum and compartment syndrome in a 14 years old girl as a complication of percutaneous radiological gastrostomy. We also review the literature for this rare complication.

\section{Case report}

A 14 years old female known case of cerebral palsy, epilepsy, spinal deformities and fixed flexion deformities of upper and lower limbs who was in long-term nasogastric feeding was admitted electively to our hospital for insertion of percutaneous gastrostomy feeding tube. She had the procedure done under conscious sedation. Size 14 Fr feeding pigtail-retained catheter was inserted percutaneously into the stomach under fluoroscopic guidance. The patient tolerated the procedure well without immediate complications (figure 1) however, she failed to tolerate feeding through the gastrostomy tube and the tube had to be clamped. She also developed frequent vomiting and increasing abdominal distension over the forty-eight hours after the procedure. 


\section{JMSCR Vol||06||Issue||03||Page 669-675||March}

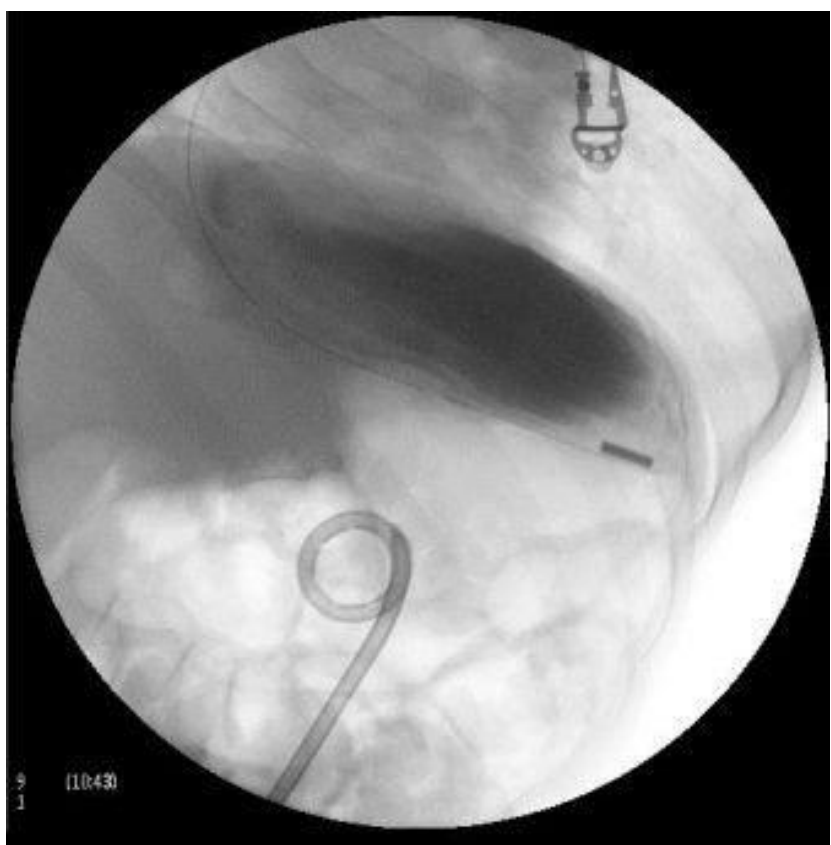

Figure 1: fluoroscopic view showing the feeding tube in the stomach.

She had abdominal $\mathrm{x}$-rays which revealed suspicious of free intraperitoneal air (figure 2).

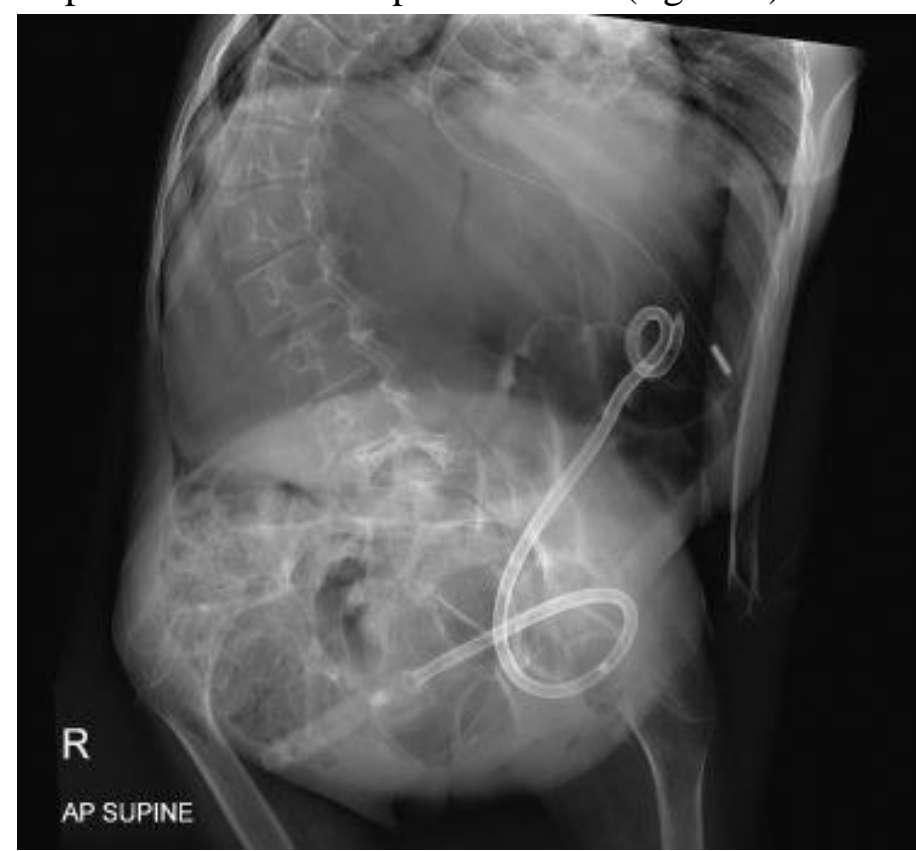

Figure 2: The abdominal $x$-ray showing the feeding tube in the stomach and free air in the peritoneal cavity together with the vertebral column and limbs deformities.

She also had an urgent abdominal CT scan with gastrograffin contrast through the nasogastric tube which showed massive pneumoperitoneum with mild free fluids in the peritoneal cavity without evidence of leak (figure 3,4).

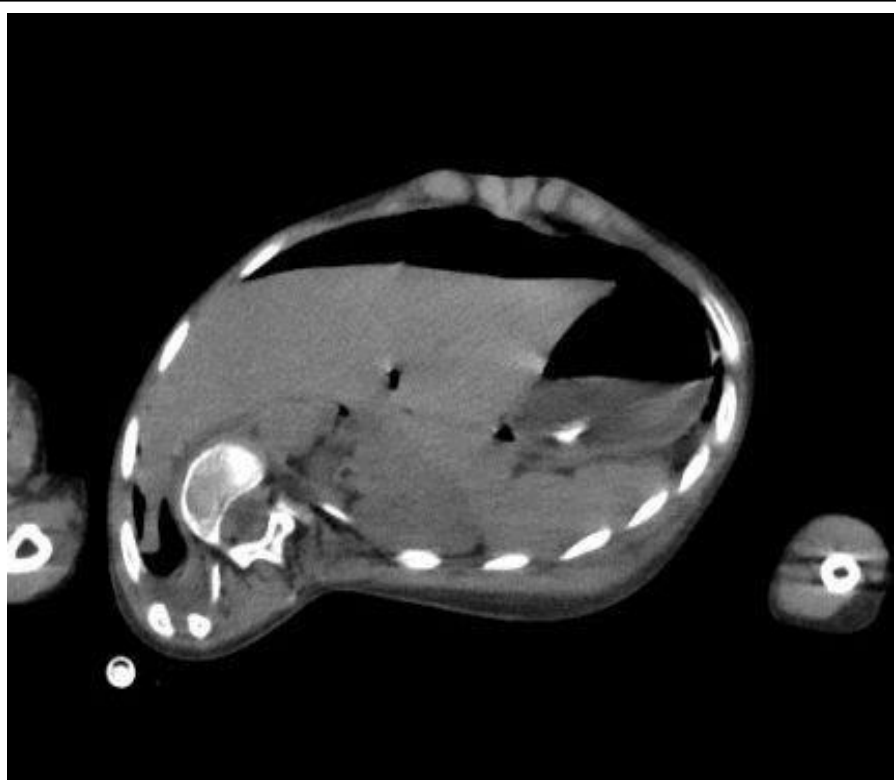

Figure 3: The CT scan of the abdomen, showing marked pneumoperitoneum and the gastrostomy tube in the stomach without evident leak.

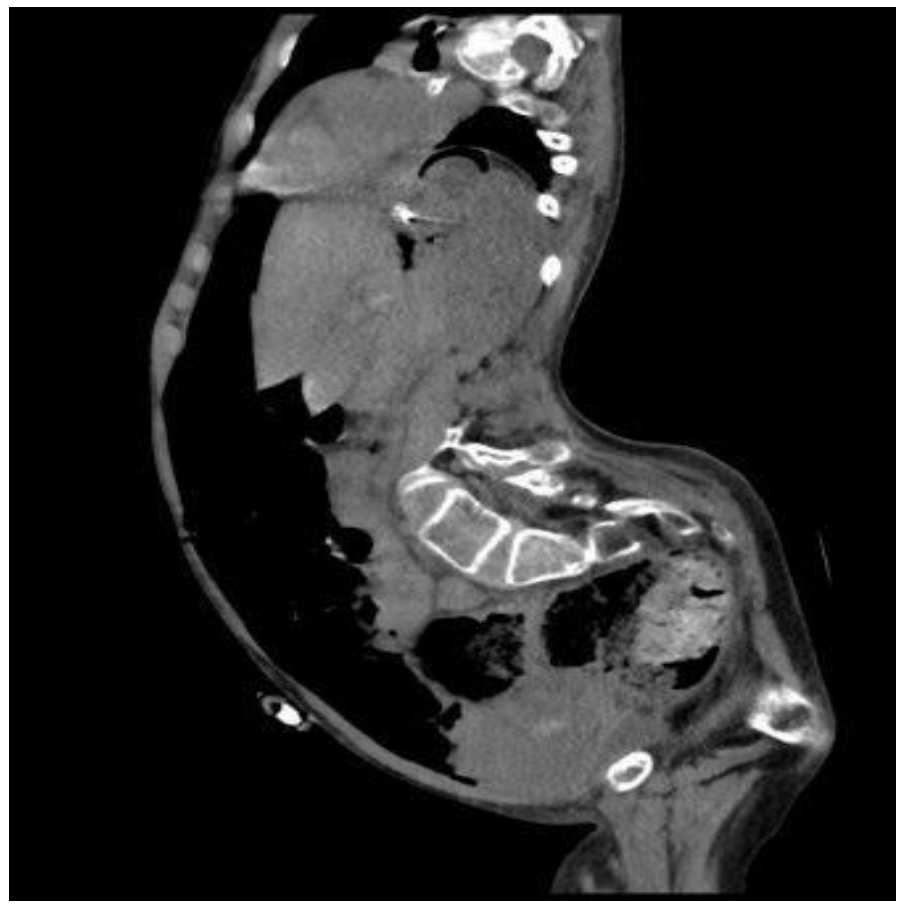

Figure 4: The CT scan (sagittal view) showing the same finding in figure 3.

Shortly after the CT scan, the patient's condition deteriorated rapidly. She became confused with pulse rate over 130/minute and systolic blood pressure below $90 \mathrm{~mm}$ of $\mathrm{Hg}$ and she started to drop her oxygen saturation. Her abdomen became more distended, tympanic and rigid. She was rushed to the operation room for laparotomy. The abdomen was explored through an upper mid line 
incision. The patient had immediate response after entering the abdomen, her pulse rate started to come down and her blood pressure started to build up. The stomach was found not fixed to the anterior abdominal wall with about $5 \mathrm{~cm}$ of the tube between the stomach and the abdominal wall. The free intraperitoneal fluids were sucked out and testing for gastric leak by methylene blue injection through the nasogastric tube demonstrates leaking around the gastrotomy tube (photograph 1). The tube was secured to the stomach with double purse string sutures and the stomach was fixed to the anterior abdominal wall. The patient was kept ventilated for 24 hours and remained hemodynamically stable. Feeding through the gastrotomy tube was assumed on the second post-operative day and was well tolerated by the patient.

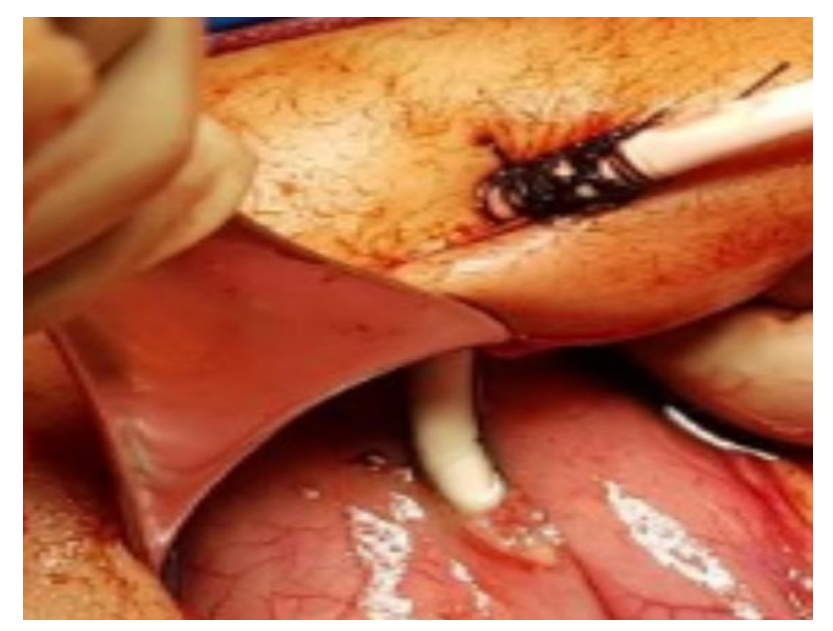

Photograph 1: intraoperative photograph showing that the stomach is not fixed to the anterior abdominal wall with about $5 \mathrm{~cm}$ of the tube between the stomach and the anterior abdominal wall with leakage of the methylene blue around the tube.

\section{Discussion}

Gastrostomy placement for nutritional support for patients with inadequate oral intake has been attempted using surgical, endoscopic, and, more recently, percutaneous radiologically guided methods. ${ }^{(2)}$

An open surgical gastrostomy was first described by Stamm in 1894 and was considered the standard for long-term enteral access and gastric decompression until percutaneous endoscopic gastrostomy (PEG) was introduced in 1980 by Gauderer et al. ${ }^{(3)}$ Since its first description, percutaneous endoscopic gastrostomy (PEG) has become the method of choice for providing enteral access and nutritional support to patients who are unable to take oral feedings. ${ }^{(4)}$ and it is almost totally replaced open feeding gastrostomy.

The percutaneous radiological gastrostomy (PRG), also known as "radiologically inserted gastrostomy," which uses fluoroscopic guidance, was first performed in 1981 by the Canadian surgeon Preshaw, ${ }^{(5,6)}$ and was devised as an alternative to PEG in cases in which passing an endoscope is difficult or risky ${ }^{(6-8)}$.

Another alternative to PEG tube is the laparoscopic approach described by Edelman et $\mathrm{al}^{(9,10)}$ in 1991. It has the same advantage of (PRG) in patients in whom endoscopy is not possible because of impassable obstructions from tumors in the pharyngoesophageal region or facial trauma. In addition, it offers the benefits of intraabdominal inspection and therefore reduces the chances of injuries during the procedure ${ }^{(11)}$.

Tension pneumoperitoneum (TP) is defined as the massive accumulation of air in the peritoneal cavity, which results in a sudden increase in intraabdominal pressure. ${ }^{(1)}$ it is a is a rare cause of abdominal compartment syndrome (ACS) with high intra-abdominal pressure caused by trapped gas leading to decreased venous return, decreased visceral perfusion and splinting of the diaphragm with consequent circulatory and respiratory compromise $^{(12)}$ and may even lead to cardiopulmonary arrest depending on the magnitude of the intraabdominal pressure ${ }^{(13)}$. Since the first recorded case of tension pneumoperitoneum following resection of a pharyngeal diverticulum ${ }^{(14)}$, there have only been a handful of case reports or small case series ${ }^{(15)}$. Various iatrogenic procedures are responsible for this complication including positive-pressure ventilation, gastric rupture due to improper 
cardiopulmonary resuscitation, gastric or duodenal ulcer perforation and endoscopy. ${ }^{(16-19)}$.

Although Minimum pneumoperitoneum is common after percutaneous endoscopic gastrostomy (PEG) tube insertion, tension pneumoperitoneum is rarely reported as a complication of the procedure. WDC Keale et al. (28) report a case of an 8-year-old microcephalic boy with spastic quadriplegia had longstanding swallowing incoordination who developed tension pneumoperitoneum and compartment syndrome immediately after insertion of percutaneous endoscopic gastrojejunostomy, which relieved by emergencydecompression. They attributed the tension pneumoperitoneum to excessive leakage of air around the gastrostomy balloon during passage of the endoscope into the distal duodenum. Iscan $\mathrm{Y}$ et $\mathrm{al}^{(29)}$ reported another case of pneumoperitoneum and with subcutaneous emphysema in a 45-year-old woman, who was diagnosed as having Neuro-Bechet's disease with swallow dysfunction happened 15 days after PEG tube insertion for long-term enteral feeding. Similarly, Bunni Jet $\mathrm{al}^{(30)}$ reported a case of abdominal compartment syndrome caused by tension pneumoperitoneum in a fit 52-year-old experienced female scuba diver following a routine training dive to $27 \mathrm{~m}$.

Percutaneous radiological gastrostomy is well established as safe, reliable and effective alternative to PEG especially in cases in which passing an endoscope is technically difficult, with few minor complications such as superficial stomal infection, minor leakage around the tube, and few major complications such as peritonitis, bleeding, deep stomal infection, aspiration, displacement of the tube requiring a repeat procedure, and sepsis. ${ }^{(31)}$

Although simple and complicated pneumoperitoneum are well-recognized complication of PEG tube insertion they are rarely described as complications of percutaneous radiological gastrostomy, to our knowledge this case is the first case of tension pneumoperitoneum complicating radiologically inserted gastrostomy. Although the exact mechanism of our patient's TP is not clearly recognized, we think of that two factors contributed significantly to its development. The first factor was a large amount of air swallowed by mouth breathing secondary to the patient neurological status. The second factor was the use of pigtail-retained feeding tube without tube gastropexy with failure to attach or fix the stomach to the anterior abdominal wall. We also believe that this complication should have been prevented by using a balloon-retained or mushroom-retained tube as pushing the inflated balloon or the mushroom against the abdominal wall would have sealed the gastrotomy opening and prevented air leakage. In fact, some authors (32-34) advocate routine use of mushroom-retained tubes particularly in stroke patients who require long-term feeding and who might attempt to pull the tube out as a result of cognitive function.

tension pneumoperitoneum is live threating condition. Early diagnosis and prompt decompression is lifesaving. Diagnosis depends on high index of suspicious. The condition should be suspected in all patients who developed Hemodynamical and respiratory compromise in addition to increasingly tympanic abdominal distension after endoscopy or abdominal percutaneous radiological procedures. the diagnosis can firmly be confirmed by plain radiographs of the chest and abdomen.

An erect chest x-ray is probably the most sensitive plain radiograph for the detection of free intraperitoneal air which shown the Dome sign demonstrated by the presence of bilateral dark crescent of gas under both hemidiaphragm. ${ }^{(35)}$

Massive free intraperitoneal air may demonstrate cupola sign which refers to non-dependent gas that rises within the abdominal cavity of the supine patient to accumulate underneath the central tendon of the diaphragm in the midline. It is seen as lucency overlying the lower thoracic vertebral bodies with well-defined superior border and ill-defined inferior margin. ${ }^{(36)}$

multiple signs of free intraperitoneal air were described on supine abdominal radiographs 
including the double wall sign also known as Riegler sign which it is a sign of pneumoperitoneum with gas outlining both sides of the bowel wall result from presence of extra and intra luminal gas, usually seen when large amounts of free gas, $>1000 \mathrm{~mL}$, present within the peritoneal cavity, the falciform ligament sign (also called the Silver sign) is a sign seen with a pneumoperitoneum resulting from outlining of the falciform ligament with free intraperitoneal gas in a supine patient and the football sign (the intraperitoneal outlines the abdominal cavity, the falciform ligament appears like the laces of a football). ${ }^{(37)}$

CT scan is considered superior to simple plain radiograph in detecting the presence of pneumoperitoneum $^{(38)}$ and usually capable of demonstrating the presence of intra-abdominal free air in patients who had no evidence of pneumoperitoneum on chest radiograph. ${ }^{(25)}$ but is usually not needed for confirmation of the diagnosis in cases of tension pneumoperitoneum as it may delay abdominal decompression.

Management of tension pneumoperitoneum like management of tension pneumothorax is immediate decompression which can be lifesaving. decompression can be achieved by percutaneous needle decompression or surgery. Many authors advocate ${ }^{(1,15,39)}$ percutaneous needle decompression either as a bridge to definitive surgical treatment or as part of conservative management in patients who are poor surgical candidates.

\section{Summary}

The percutaneous radiological gastrostomy (PRG) was devised as an alternative to PEG for enteral feeding in cases in which passing an endoscope is difficult or risky. Although few cases of tension pneumoperitoneum were reported as complication of PEG tube insertion, it was not reported as complications of percutaneous radiological gastrostomy. Appropriate selection of gastrostomy tube together with fixation of the stomach to the anterior abdominal wall during and after the procedure is important for prevention of this complication. Tension pneumoperitoneum is live threating condition, itsearly diagnosis and prompt decompression are considered as lifesaving.

Conflict of interest: non-declared

\section{References}

1. Symeonidis $\mathrm{N}$, Ballas $\mathrm{K}$, Pavlidis E, Psarras K, Pavlidis T, Sakantamis A. Tension Pneumoperitoneum: A Rare Complication of Upper Gastrointestinal Endoscopy. JSLS: Journal of the Society of Laparoendoscopic Surgeons. 2012;16 (3):495-497.

2. Shin JH, Park A-W. Updates on Percutaneous Radiologic Gastrostomy/ Gastrojejunostomy and Jejunostomy. Gut and Liver. 2010;4(Suppl 1): S25-S31. doi:10.5009/gnl.2010.4. S1. S25

3. Gauderer MW, Ponsky JL, Izant RJ., Jr Gastrostomy without laparotomy: a percutaneous endoscopic technique. J Pediatr Surg. 1980; 15:872-875.

4. Wiesen AJ, Sideridis K, Fernandes A, et al. True incidence and clinical significance of pneumoperitoneum after PEG placement: a prospective study. Gastrointest Endosc. 2006; 64:886-889.

5. Preshaw RM A percutaneous method for inserting a feeding gastrostomy tube. Surg Gynecol Obstet. 1981;152659- 660

6. Löser C, Aschlb G, Hebuternec X, et al. ESPEN guidelines on artificial enteral nutrition - Percutaneous endoscopic gastrostomy (PEG) ClinNutr. 2005; 24:848-61.

7. De Baere T, Chapot R, Kuoch V, et al. Percutaneous gastrostomy with fluoroscopic guidance: Single-centre experience in 500 consecutive cancer patients. Radiology. 1999; 210:651-4

8. Ozmen MN, Akhan O. Percutaneous radiologic gastrostomy. Eur $\mathrm{J}$ Radiol. 2002; 43:186-95. 
9. Edelman DS, Unger SW. Laparoscopic gastrostomy. Surg. Gynecol. Obstet. 1991; 173: 401.

10. Edelman DS, Arroyo PJ, Unger SW. Laparoscopic gastrostomy versus percutaneous endoscopic gastrostomy: A comparison. SurgEndosc. 1994; 8:47-9.

11. Reck T, Köckerling F, Horbach T, Hohenberger W: Perkutanelaparoskopische Gastrostomie (PLG). Zentralbl Chir 1997; 122:700-705.

12. Chan SY, Kirsch CM, Jensen WA, Sherck J. Tension pneumoperitoneum. West J Med 1996; 165: 61-64

13. Deenichin GP. Abdominal compartment syndrome. Surg Today. 2008; 38: 5-19

14. Conole FD, D'Angelo AA. Resection of pharyngeal diverticulum with spontaneous development of tension pneumoperitoneum. Am J Surg 1952; 83:580-3.

15. Chiapponi C, Stocker U, Körner M, Ladurner R. Emergency percutaneous needle decompression for tension pneumoperitoneum. BMC Gastroenterol 2011; 11:48.

16. García-Santos E, Puerto-Puerto A, Sánchez-García S, Ruescas-García FJ. Alberca-Páramo A, Martín-Fernández J. [Abdominal compartment syndrome by tension pneumoperitoneum secondary to barotrauma. Presentation case]. Cir Cir. 2015 Sep-Oct;83(5):429-32.5

17. Burdett-Smith P, Jaffey L. Tension pneumoperitoneum. Journal of Accident \& Emergency Medicine. 1996;13(3):220221.

18. Lu TC, Chen SY, Wang HP, Lee CC. Tension pneumoperitoneum following upper gastrointestinal endoscopy. J Formos Med Assoc. 2006; 105: 431-433

19. Richmond BK, Mullins B, Jackson M, Dyer B, Agarwal S. Tension pneumoperitoneum resulting from endoscopic duodenal perforation: a case report. W V Med J. 2006 NovDec;102(6):26-7.

20. Park WY, Lee TH, Lee JS, Hong SJ, Jeon SR, Kim HG, Cho JY, Kim JO, Cho JH, Lee SW, Cho YK. Reappraisal of Pneumoperitoneum After Percutaneous Endoscopic Gastrostomy. Intest Res. 2015 Oct;13(4):313-7.

21. Hillman KM. Pneumoperitoneum--a review. Crit Care Med. 1982 Jul;10(7): 476-481.

22. Hill HF, Bunting J, Wood RD, Temple JG. The significance of radiological pneumoperitoneum in the diagnosis of postoperative peritonitis. J R Coll Surg Edinb. 1978 Sep;23(5):303-4.

23. Nazarian A, Cross W, Kowdley GC. Pneumoperitoneum after percutaneous endoscopic gastrostomy among adults in the intensive care unit: incidence, predictive factors, and clinical significance. Am Surg. 2012 May;78 (5):591-4.

24. Roberts PA, Wrenn K, Lundquist S. Pneumoperitoneum after percutaneous endoscopic gastrostomy: a case report and review. J Emerg Med. 2005 Jan;28(1):458.

25. Dulabon GR, Abrams JE, Rutherford EJ. The incidence and significance of free air after percutaneous endoscopic gastrostomy. Am Surg. 2002 Jun;68 (6):590-3. PubMed

26. Lee JY, Park KS. Pneumoperitoneum After Percutaneous Endoscopic Gastrostomy: Does It Have Clinical Significance? Intestinal Research. 2015;13(4): 295-296. doi:10.5217/ir.2015.13.4.295.

27. Milanchi S, Allins A. Early pneumoperitoneum after percutaneous endoscopic gastrostomy in intensive care patients: sign of possible bowel injury. Am J Crit Care. 2007; 16:132-136.

28. Kealey WD, McCallion WA, Boston VE. Tension pneumoperitoneum: a potentially 
life-threatening complication of percutaneous endoscopic gastrojejunostomy. J Pediatr Gastroenterol Nutr. 1996 Apr;22(3):334-5

29. Iscan Y, Karip B, Ozcabi Y, Ağca B, Alahdab Y, Memisoglu K. Pneumoperitoneum with subcutaneous emphysema after percutaneous endoscopic gastrostomy. Case Rep Surg. 2014; 2014:726878.

30. Bunni J, Bryson PJ, Higgs SM. Abdominal compartment syndrome caused by tension pneumoperitoneum in a scuba diver. Ann R Coll Surg Engl. 2012 Nov;94(8): e237-9

31. Wollman B, D'Agostino HB, Walus-Wigle JR, Easter DW, Beale A. Radiologic, endoscopic, and surgical gastrostomy: an institutional evaluation and meta-analysis of the literature. Radiology. 1995; 197:699-704.

32. Laasch HU, Martin DF. Radiologic gastrostomy. Endoscopy. 2007; 39:247255

33. Funaki B, Zaleski GX, Lorenz J, Menocci PB, Funaki AN, Rosenblum JD, Straus C, Leef JA. Radiologic gastrostomy placement: pigtail- versus mushroomretained catheters.

34. Han K, Kim MD, Kwon JH, Kim YS, Kim GM, Lee J, Choi W, Won JY, Lee DY. Randomized Controlled Trial Comparing Radiologic Pigtail-Retained Gastrostomy and Radiologic Mushroom-Retained Gastrostomy. J VascIntervRadiol. 2017 Dec;28(12):1702-1707.

35. Kasznia-Brown J, Cook C. Radiological signs of pneumoperitoneum: a pictorial review. Br J Hosp Med (Lond). 2006 Dec;67(12):634-9.

36. Marshall Geoffrey B. "The Cupola Sign." Radiology 241, no. 2 (November 1, 2006): 623-624.

37. Pinto A, Miele V, Schillirò ML, Nasuto M, Chiaese V, Romano L, Guglielmi G. Spectrum of Signs of Pneumoperitoneum.
Semin Ultrasound CT MR. 2016 Feb;37(1):3-9.

38. Stapakis JC, Thickman D. Diagnosis of pneumoperitoneum: abdominal CT vs. upright chest film. J Comput Assist Tomogr. 1992; 16:713-716.

39. Alun E. Jones, Dean Godfrey, Guy F. Nash. Tension pneumoperitoneum: innovative decompression of this general surgical emergency April 2011 Surgical Techniques Development v. 1, n. 2, p. e21, oct. 2011. 